\title{
How to drive your surgeon crazy
}

W hy would anyone want to drive their surgeon crazy? Do patients intentionally do this? Probably not, I mean, why would you?

The surgeon is supposed to be the soul of patience. He is supposed to treat you and make your problems go away. But first, he has to diagnose you. Suppose you wanted to drive your surgeon crazy for some reason best known only to you. This is how you could do it. Remember, this is secret information so be careful how you use it, and don't quote me.

The first and best way: Never answer a question. If the surgeon asks, "How long have you had this", always reply, "A long time". It drives them crazy, and it's none of their business anyway. After all, they are just going to ask you why you didn't come sooner. You don't really want to be there anyway; it's only because the ointment and beetroot didn't work. Even better, answer a different question. Question: "How long have you had this"; answer: "It really hurts".

Make a big point about the difference between your advice and your family doctor's advice. "So how come you are telling me something different than my doctor said?" This is a real winner. The surgeon has to explain that he is a surgeon, so the advice is different. This is guaranteed to get his attention because he has to explain his qualifications and even explain why you were referred. You can say, "I think I like my doctor's advice better". Also, before you come for the visit, look in the mirror and practise a suspicious look meaning, "Of course you are going to recommend surgery, that's how you get rich". Don't say it, just practise the look. You've won when the surgeon starts to reassure you.

Once you've gotten the confused look perfected, try this: "I don't know why my doctor sent me". The surgeon has no way out of this. If he says, "I don't know either", or if he says, "Your doctor is worried you have a ganglion", you can say, "I already knew that", so you've won again. Try saying, "It went away, but I thought I would come anyway".

You can mispronounce simple words, so see if he will correct you. Try saying "gangrion". Then when he corrects you, you can say smugly, "I've always called it gangrion". But be careful, the goal is to assert the upper hand, not to look like an idiot.

Get upset when the surgeon says you have to wait four months for surgery. Practice a pout, but don't throw a tantrum; that is going too far and is counterproductive. Just conjure up sympathy. Do your homework before the visit. This is a lot like, "My dog ate my homework", but being older and wiser, you can come up with a better reason as to why you should have surgery right away and why the doctor should cancel someone else so you can get in. Do not say, "I'm going to Florida". Even if you stay in a trailer in Florida, this excuse will not work.

Ask to get in right away because it is only a little operation. A pine sliver in a finger need-

ing urgent removal is a good one. After all, it will only take 15 min, right?

Dress funny. The surgeon likes to think he is a minor Sherlock Holmes who is able to diagnose by mannerisms and little things he sees. So wear your strangest clothing. Dressing like a Morris dancer is good, or a character from a Monty Python sketch. Be careful. Saying, "Not much of a hospital, is it", might bring the response, "Best one in Dibble County, sir".

Act as if you expected surgery on the first visit, and are disappointed you have to come back for the actual operation. This shows the surgeon how trivial you think the operation is, and how valuable your time is. Keep at it, you are gaining the upper hand.

Always come to the visit with all your relatives, but for special effect, bring your strangest ones. Uncle Alfred with the strabismus and 1946 dental work is a nice touch, especially if he is deaf. Prepare him to ask, "What did he say?" when he sees the surgeon speaking. Having to shout is a good way to keep the surgeon off balance.

You know you've succeeded in driving your surgeon crazy when he gives you anything you want just to get you out of the office. This is the time to use your advantage. Wait until the visit is over, then pull out your insurance form. He'll sign anything now.

Another way to tell: Look for two things. The telltale twitch in your surgeon's face, and how he gets up and slumps toward the door.

Now the visit is over. But look on the bright side.

You can always come back! 